\title{
Age-related deterioration of a physiological function in the branching coral Acropora palmata
}

\author{
Erik H. Meesters ${ }^{1}$, Rolf P. M. Bak ${ }^{1,2, *}$ \\ ${ }^{1}$ Institute of Systematics and Population Biology, PO Box 94766, 1090 GT Amsterdam, The Netherlands \\ ${ }^{2}$ Netherlands Institute for Sea Research (NIOZ), PO Box 59, 1790 AB Den Burg, The Netherlands
}

\begin{abstract}
Regeneration potential of the branching coral Acropora palmata (Lamarck, 1816) was assessed at distances of 3,12 , and $66 \mathrm{~cm}$ from the branch tip. Artificial lesions (colony surface wounds) were made on 3 randomly selected branches of 21 colonies and regeneration was followed over $30 \mathrm{~d}$. Regeneration was measured as tissue regrowth $\left(\mathrm{mm}^{2} \mathrm{~d}^{-1}\right)$ during the first $6 \mathrm{~d}$ of regeneration and as the slope of an exponential regression of lesion surface area through time. Both measurements showed that regenerative potential could be fitted to an exponential function, decreasing from tip to base. Regeneration capability decreases rapidly in the first $25 \mathrm{~cm}$ from the distal end and only slowly beyond. This decrease in regeneration capabiluty appears to be related to polyp age and constitutes the first report of potential senescence in corals. There are direct consequences for population dynamics in this branching Acropora species. Invasion of lesions by excavating sponges will occur more in proximal portions of the colony because the slow regeneration potential in this area results in long-term skeletal exposure. This may promote the fragmentation of branches with a length sufficient to ensure a high survivorship.
\end{abstract}

KEY WORDS: Regeneration - Modular organisms Corals - Ecology - Damage - Age Senescence Growth $\cdot$ Scleractinia

\section{INTRODUCTION}

Corals are basically modular organisms (sensu Chapman 1981), every module (i.e. polyp) in a coral colony having the same potential for any physiological function. However, in some coral species parts of colonies appear to be able to differentiate, becoming functionally distinct from the rest of the colony. For instance, parts are more sensitive to mortality (Tunnicliffe 1978, 1981) or have a higher fecundity (Harrison \& Wallace 1990, Soong \& Lang 1992, Van Veghel \& Kahmann 1994).

Functional separation of colony parts appears to be most developed in branching corals (Soong \& Lang 1992). Jackson (1979) postulated that branching, treelike morphologies of clonal organisms must have a strong commitment to their limited areas of attachment (e.g. defence structures on proximal parts). However,

- Addressee for correspondence (at NIOZ) branching corals do not appear to be strongly committed to their bases (Highsmith et al. 1980). The potential for breakage is high in arborescent corals because branches grow rapidly in length, are produced in large numbers, and break readily as a result of biological and physical disturbances. If branches do not break as a result of disturbances because they may ultimately break of their own weight (Maragos 1972, Bak 1976). Breaking of branches, fragmentation, is very common in branching corals and probably evolved as an adaptation to high energy environments (Highsmith 1982). Dead parts on arborescent colonies are readily infected by boring sponges that weaken the skeletal structure (Tunnicliffe 1978, Gladfelter 1982). Tunnicliffe (1978) proposed that excavations by boring sponges may promote fragmentation in the coral Acropora cervicornis and aid in its asexual reproduction.

The detachment of branches during disturbances may constitute the primary mode of reproduction and distribution for Acropora palmata (Highsmith et al. 1980, Highsmith 1982), and, in a study on the origin of 
A. palmata colonies, Highsmith (1982) found an average of $69 \%$ asexually derived colonies. Survival of $A$ palmata fragments increases with branch length (Highsmith et al. 1980). Bak (1983) showed that $A$. palmata has a high capability to regenerate and heal damage compared to non-branching species. Fragmentation anc regeneration thus appear to be deeply integrated within the life history of this species.

In this paper we show intra-colony differences in a physiological function, namely regeneration, to be linked with polyp age in the branching coral Acropora palmata. These differences may affect colony fragmentation patterns and promote breakage of branches after having reached a certain length.

\section{MATERIALS AND METHODS}

A total of 21 colonies of the branching species Acropora palmata (Lamarck) were haphazardly selected on the fringing reef in front of the Curaçao Seaquarium at 2 to $4 \mathrm{~m}$ depth. Curaçao is part of the Netherlands Antilles and is situated in the southern Caribbean. At each colony, 3 branches were randomly chosen. Each branch received a single lesion at approximately 3,12 , or $66 \mathrm{~cm}$ from the tip of the branch. In most branches, $66 \mathrm{~cm}$ was close to the base of the branch and the base of the colony. Lesions were made with a submersible pneumatic drill powered by a SCUBA tank and equipped with a small grinding point that created cylindrical patches of scraped skeleton of approximately $1 \mathrm{~cm}$ diameter and $2 \mathrm{~mm}$ depth. Lesion area was measured with a Plexiglas ruler divided into $2 \mathrm{~mm}$ squares. At the start of the experiment lesion depth was measured with calipers to calculate the surface area of the lesion wall. This area was included in the estimation of the total lesion area. All lesions were made within $3 \mathrm{~h}$ on November 7, 1991.

Regeneration of the different groups of lesions was analysed by a randomized blocks design followed by pairwise comparisons by the Tukey HSD test (Sokal \& Rohlf 1981). As dependent variables we used (1) regeneration rate, i.e. area recovered $\left(\mathrm{mm}^{2} \mathrm{~d}^{-1}\right)$ during the first $6 \mathrm{~d}$ (sensu Meesters \& Bak 1993) and (2) the regression slope describing the regeneration process (Bak 1983, Meesters et al. 1992, Meesters \& Bak 1993). Regression slopes were calculated by a non-linear line fitting program. Because regeneration slows down over time, lesions do not always close completely. Initially intrinsic and later extrinsic factors, such as settlement of organisms in the lesions, can be responsible. Lesion surface area $(S)$ is best described by the model Lesion Size $=S_{\infty}+\left[S_{\max } \times 10^{\text {(Slope } \times \text { Days) }}\right]$ (Meesters et al. 1994). This model simply states that lesion surface area decreases exponentially to an asymptote $\left(S_{\infty}\right) . S_{\max }$ is the maximum area that will be regenerated. $S_{\max }$ plus $S_{\infty}$ make up the initial lesion surface area.

Because differences in initial lesion area and lesion depth can affect regeneration rate (Bak \& Steward-van Es 1980, Meesters unpubl.), the 3 groups of lesions (3, 12 , and $66 \mathrm{~cm}$ from branch tip) were tested for differences in these parameters by a 1-way ANOVA.

The assumptions underlying the statistical analyses were assessed by graphical methods (Wilkinson 1989). If necessary, data were transformed (logarithmically) and means reported as geometric means with $95 \%$ confidence limits.

\section{RESULTS}

\section{Initial lesion parameters}

Mean lesion surface area and lesion depth, directly after lesion infliction, did not differ between the 3 groups of 3,12, and $66 \mathrm{~cm}$ from branch tip (1-way ANOVA, $p=0.64$ and $p=0.49$ for, respectively, surface area and depth). Overall, mean lesion surface area and lesion depth ( $\mathrm{SE}$ in parentheses, $\mathrm{n}=21$ ) were respectively $159.4 \mathrm{~mm}^{2}(5.5)$ and $1.90 \mathrm{~mm}(0.11)$.

\section{Visual aspects of regeneration}

The 2 groups of lesions closest to the top of the branch started their regeneration with the formation of a very thin transparent veneer of undifferentiated tissue, which was almost invisible during the first week (Fig. 1A). Apparently no calcification was taking place. During this phase the new tissue was transparent and appeared completely white because of the underlying white skeleton and the lack of zooxanthellae. At the end of the first week filamentous algae could be observed to have settled on the bare unrecovered skeleton (Fig. 1B). In the second week the new tissue layer grew thicker, polyp outlines, small polyps, and calices emerged, and the new tissue started to develop pigmentation (Fig. 1C). Orientation of the new polyps was distinct from that of the surrounding polyps and appeared rather random. This random aspect however disappeared, and after 1 to 2 mo any trace of lesions had disappeared.

Proximal lesions regenerated very differently. Tissue, polyps, and skeleton were formed simultaneously, but much more slowly than in the distal lesions. There was no quick expansion of tissue, but a slow growth inwards from the boundaries of the lesion. Often a thick pigmented lip would develop at the edge and start growing inwards. This new pigmented tissue was lighter in colour than the undamaged tissue surrounding the lesion. 

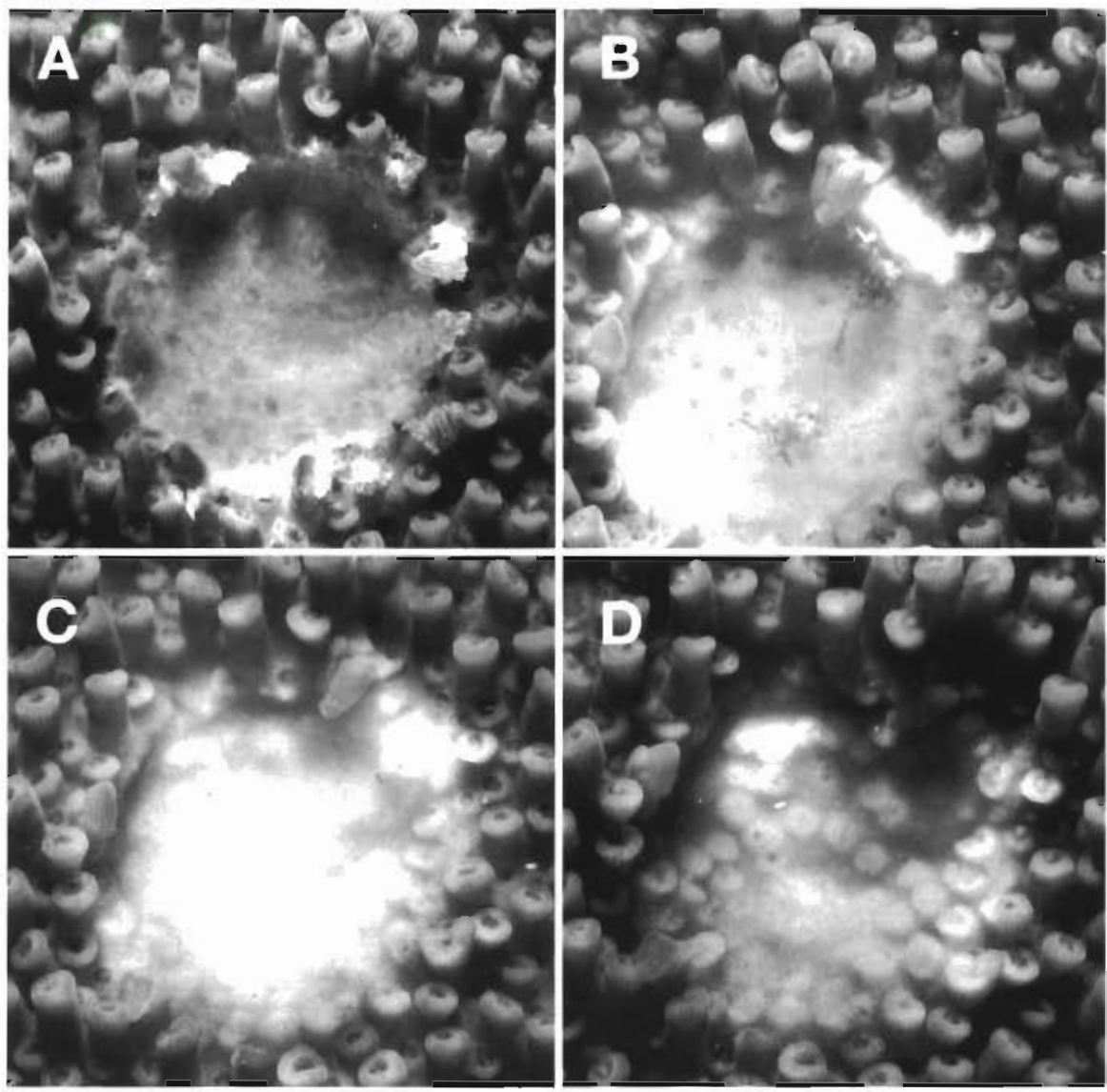

Fig. 1. Acropora palmata. Regeneration of a lesion, situated close to the tip of a branch, in progress from top left to bottom right. (A) Directly after lesion infliction small skeletal remains are still visible. (B) After 1 wk lesion has been covered completely by a thin veneer of new tissue. Two tufts of filamentous algae are still protruding through the new tissue. (C) Halfway through the second week outlines of new polyps emerge. New tissue layer appears more solid. (D) After 2 wk formation of new polyps almost finished. Lesions flush with skeleton

\section{Lesion regeneration}

\section{Lesion surface area}

Lesion regeneration of Acropora palmata was also quantitatively, in terms of regenerated area, different at different places on colony branches (Fig. 2). Within $1 \mathrm{wk}, 33 \%$ of the lesions nearest the tips of branches had been closed. After $12 \mathrm{~d}$ percentages of closed lesions were 62,29 , and 0 for respectively distal, middle, and proximal treatments (Test of independence; $G=24.1, \mathrm{df}=2, \mathrm{p}<0.0001)$. At the end of the experiment ( $30 \mathrm{~d}$ ) all lesions were completely closed, except for $33 \%$ of the proximal lesions, which were still open.

\section{Regeneration rate}

During the first week the decrease in lesion area was very fast (Fig. 2). The mean area recovered per day

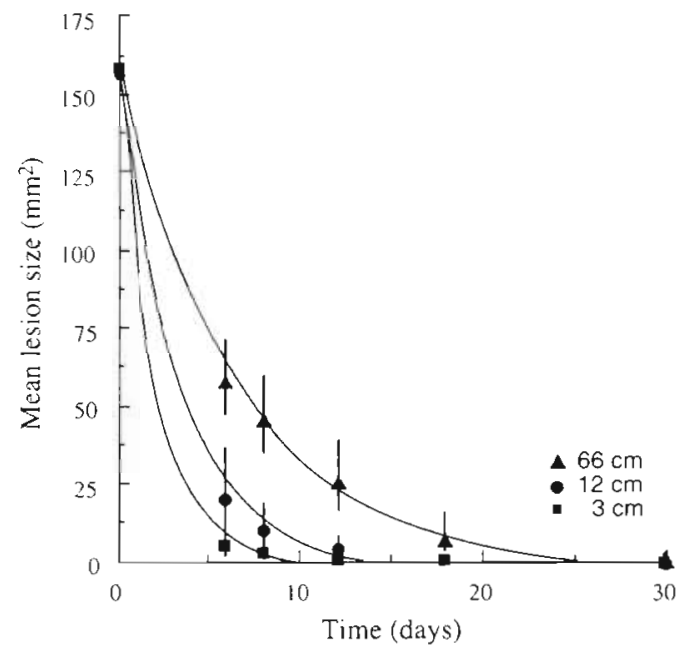

Fig. 2. Acropora palmata. Regeneration of lesions at 3,12, and $66 \mathrm{~cm}$ from branch tip. Mean lesion surface area $(95 \%$ confidence limits) measured at time intervals during regeneration $(\mathrm{n}=21)$. Lines show the average regression line as calculated with a non-linear line-fitting program (see Table 1) 


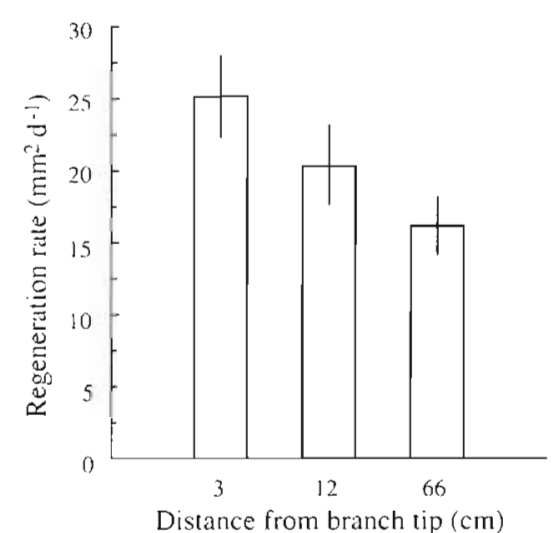

Fig. 3. Acropora palmata. Initial regeneration rates of lesions. Mean daily growth of tissue from the lesion boundaries inwards during the first $6 \mathrm{~d}$ after lesion infliction. Lesions at 3 , 12 , and $66 \mathrm{~cm}$ from branch tip. Vertical lines indicate $95 \%$ confidence limits
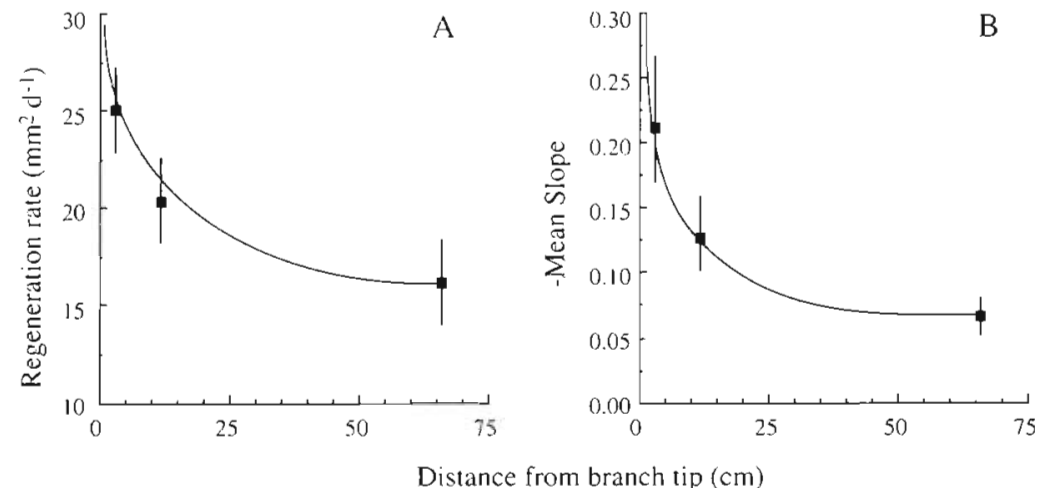

Fig. 4. Acropora palmata. Regeneration potential expressed as (A) regeneration rate and (B) regression slope, as a function of distance from branch tip. Values are means and $95 \%$ confidence limits ( $n=21$ for each data point). Mean slope is geometric mean. Regressions: Mean area $\mathrm{d}^{-1}=28.8$ $6.875 \log _{10}\left(\right.$ Distance) $, r^{2}=0.34, p<0.00001_{i}$ mean slope $=-0.323$ Distance $^{-0382}$, $\mathrm{r}^{2}=0.43, \mathrm{p}<0.00001$ during the first $6 \mathrm{~d}$ showed that regeneration rates increased toward the tip of the branch (Fig. 3). Regeneration was fast for lesions closest to the branch tip, slow for lesions furthest from the tip, and intermediate for the middle group. The mean regeneration rates differed significantly $(\mathrm{p}<0.01$ for all pairwise comparisons except $3 \mathrm{~cm}$ vs $12 \mathrm{~cm}$ where $p=0.012$, Tukey HSD test). On average, tissue in the lesions had regenerated at approximately $20.5 \mathrm{~mm}^{2} \mathrm{~d}^{-1}$ after the first $6 \mathrm{~d}$.

\section{Regeneration regression coefficients}

The exponential model used to describe regeneration proved to be a close approximation to the actual regeneration process (Fig. 2, Table 1).

The estimated parameters (Table 1) indicate that Acropora palmata is probably able to regenerate lesions larger than those made in this study. $S_{\infty}$ (the asymptotic lesion surface area resulting if lesions do not regenerate

Table 1. Acropora palmata. Regression parameters for lesions 3, 12 and $66 \mathrm{~cm}$ from branch tip. Results of non-linear fitting of lesion sizes to the model: Lesion Size $=S_{\infty}+\left[S_{\max } \times 10^{\text {ISlope }} \times\right.$ Daysi) $]$. Means are based on parameters for each individual lesion $(n=21)$

\begin{tabular}{|cccc|}
$\begin{array}{c}\text { Distance } \\
(\mathrm{cm})\end{array}$ & $\begin{array}{c}S_{\infty} \\
(95 \% \mathrm{CL})\end{array}$ & $\begin{array}{c}S_{\max } \\
(95 \% \mathrm{CL})\end{array}$ & $\begin{array}{c}- \text { Slope } \\
(95 \% \mathrm{CL})^{\mathrm{A}}\end{array}$ \\
\hline 3 & $-1.3( \pm 1.03)$ & $164.3( \pm 6.2)$ & $0.213(0.170 / 0.267)$ \\
12 & $-2.9( \pm 2.40)$ & $160.1( \pm 5.6)$ & $0.127(0.095 / 0.170)$ \\
66 & $-3.3( \pm 8.30)$ & $162.3( \pm 9.2)$ & $0.065(0.050 / 0.085)$ \\
& & & \\
a Geometric mean & &
\end{tabular}

completely) is slightly negative. $S_{\max }$ (maximum lesion that will be regenerated completely) is larger than the average initial lesion area of $159.4 \mathrm{~mm}^{2}$.

Mean regression slopes of the regeneration at the 3 distances differed significantly $(p<0.01$ for all pairwise comparisons. Tukey HSD test). The slope was steepest (fastest regeneration) for the lesions at $3 \mathrm{~cm}$ from the tip, intermediate for the lesions at $12 \mathrm{~cm}$, and least steep in the lesions at $66 \mathrm{~cm}$ from the branch tip.

\section{Regeneration gradient}

Both regression parameters (coefficients and rates) decreased from distal to proximal over branches of Acropora palmata (Fig. 4). The calculated regression lines, which are highly significant, describe regeneration at any distance from the branch tip. The graphs indicate an extremely high potential for regeneration. close to the tip of the branch. This capacity decreases very rapidly within the first $25 \mathrm{~cm}$. Beyond that the regeneration potential appears to change much more slowly.

\section{DISCUSSION}

All of our experimental data show regeneration capability to decrease rapidly, from tip to base, along branches of Acropora palmata. The inevitable question is, does this gradient in regeneration arise from extra- or intra-colony causes? And, subsequently, what are the ecological consequences? 


\section{Potential external causes}

Environmental conditions are known to differ inside branched colonies, e.g. light and nutrient availability (Chamberlain \& Graus 1975). In the present study irradiance could not have been limiting because all lesions were situated on the upperside of branches, without any shadowing. Chamberlai \& Graus (1975) found less food availability inside tightly branched colonies. However, branching in the Acropora palmata colonies of our study was not very dense and branches were not fused into dense stands. The highly exposed location of the experimental colonies, at 2 to $3 \mathrm{~m}$ depth, facing incoming waves, also precludes food limitation as a possible reason for the regeneration gradients. Moreover, because the number of branches and branch orientation differed substantially between our experimental colonies, any environmental effect that is related to those factors, would have produced regeneration rates of proximal lesions that varied much more than those found in this study (Table 1)

\section{Potential internal causes}

Physiological effects

The observed gradient in regenerative potential is very steep at the tip of the branch, decreasing only very slowly beyond the distal $25 \mathrm{~cm}$. This immediately implies a relation of regeneration to the main centers of growth in branching corals, i.e. the branch ends. Regeneration is known to reduce growth, indicating that energy supplies are limited (Bak 1983, Meesters et al. 1994). The vigorous growth (linear extension) of the zooxanthellae-free branch ends in Acropora primata requires the mobilisation of energy from the tissue containing zooxanthellae (Pearse \& Muscatine 1971, Fang et al. 1989). This tissue often appears not to produce gametes (Harrison \& Wallace 1990, Soong \& Lang 1992). Very likely mobilised energy is easily reallocated to another energy-demanding process, such as regeneration. This may explain the observed gradient. The availability of mobilised energy probably decreases very rapidly from branch tip to branch base.

\section{Age}

Most polyps at $66 \mathrm{~cm}$ from the tip will be approximately 7 yr older than polyps at $3 \mathrm{~cm}$ from the tip, assuming continual growth of branch end (Bak 1983). The directional growth of Acropora palmata branches creates an age gradient with mostly young polyps at the tip and mostly old polyps at the base. Apparently, regeneration of young polyps is very fast and regeneration capacity decreases rapidly during the first 2 to 3 yr of polyp life (approximately 18 to $24 \mathrm{~cm}$ linear growth). This means (see Fig. 4) that regeneration rates at the branch tip should even be higher than those measured at $3 \mathrm{~cm}$ from the tip. Regeneration of damaged branch tips has been observed to occur within $1 \mathrm{~d}$ (E.H.M. pers. obs.). Rapid regeneration of young polyps in new colonies would also be an effective strategy to cope with the high mortality experienced by juvenile colonies (Connell 1973, Bak \& Engel 1979). Tissue in basal regions of colonies of A. palmata appears more vulnerable and less vigorous than at branch ends. Gladfelter (1982) observed that the white band disease progresses from proximal to distal, possibly indicating a higher vulnerability of the older parts of the colony.

Clonal organisms theoretically have indeterminate growth, and senescence, a breakdown in the efficiency of functioning of an organism with age, appears to be almost absent in clonal plants (Harper 1977). However, senescence of the modules of clonal growth, mostly involving proximal margins, has been reported many times (e.g. Watt 1947, Kershaw 1962). Palumbi \& Jackson (1983) reported senescence in the bryozoan Steginoporella sp. Their conclusion was partly based on results that indicated loss of regenerative potential in proximal regions. Distal regions of the bryozoan grew vigorously and had high overgrowth ability, while proximal regions slowly deteriorated. Higher mortality of proximal parts of colonies, rapid distal growth, and high overgrowth ability of distal parts have also been observed in Acropora spp. (Bak \& Criens 1981, Tunnicliffe 1981), but these were not regarded as signs of senescence. Also, new branches do not develop in older parts of the colony, but only at the growing branch tips or in new tissue that is formed when branches fracture (authors' pers. obs.). The regeneration data presented here, combined with the characteristics on growth, mortality, and competitive ability, indicate that senescence occurs in older sections in coral colonies.

\section{Fragmentation}

The possible adaptive significance of partial senescence in Acropora palmata may lie in the promotion of fragmentation. Fragmentation and dispersal of fragments that have a high chance of survival will increase the species' chances of a successful rapid invasion of new space in the same area (Highsmith 1982). Fragmentation will also decrease the possibility of food and light limitation within the colony (Chamberlain \& Graus 1975). Slow regeneration at the base of the 
branch increases the chances of infection by boring sponges. Sponge excavations weaken the skeleton substantially (Chamberlain 1978, Tunnicliffe 1978). Gladfelter (1982) noticed that excavating sponges became increasingly prevalent in dead parts of older branches. After infection the branch will continue to grow while its strength will decrease where the sponge is excavating the skeleton: at the proximal end. Fragmentation will occur at some stage, probably as a result of physical disturbance, and the fragment is likely to be in a size class that will have a high chance of survival.

Highsmith et al. (1980) showed that fragment survival of Acropora palmata branches is dependent on branch length. However, after a certain length the chances of survival no longer increase (Fig. 4 in Highsmith et al. 1980). For a coral species that appears to depend mainly on asexual recruitment for its survival, incorporation of a process that increases the chances of fragmentation after branch survival becomes independent of branch length seems logical.

Regeneration of basal regions in branches that have attained a considerable length is still high when compared with other species (Meesters et al. 1992, Meesters \& Bak 1993). This means that the fractured area of the parental colony will regenerate relatively rapidly. The new polyps and tissue will produce new branches within a short period of time.

\section{CONCLUSIONS}

Regeneration capability of branches of Acropora palmata decreases exponentially from tip to base. This appears to constitute the first evidence of senescence in a coral because polyp age generally increases toward the base of the colony. Slower regeneration in proximal parts of the colony may promote infestation by excavating sponges that will augment the chances of fragmentation of branches with lengths that ensure a high survivorship of fragments.

Acknowledgements. We thank the Carmabi Institute for providing logistic support and O. Frans, F. Isabella and A. Thiel for diving and other assistance in the field. We thank 3 anonymous reviewers for their suggestions. This research was supported by a grant from the Netherlands Foundation for the Advancement of Tropical Research (WOTRO) W84-311.

\section{LITERATURE CITED}

Bak RPM (1976) The growth of coral colonies and the importance of crustose coralline algae and burrowing sponges in relation with carbonate accumulation. Neth J Sea Res 10:285-337

Bak RPM (1983) Neoplasia, regeneration and growth in the reef-building coral Acropora palmata. Mar Biol 77:21-227
Bak RPM, Criens SR (1981) Survival after fragmentation of colonies of Madracis mirabilis, Acropora palmata and A. cervicornis (Scleractinia) and the subsequent impact of a coral disease. Proc 4th int Symp Coral Reefs 2: $221-227$

Bak RPM, Engel MS (1979) Distribution, abundance and survival of juvenile hermatypic corals (Scleractinia) and the importance of life-history strategies in the parent coral community. Mar Biol 54:341-352

Bak RPM, Steward-van Es Y (1980) Regeneration of superficial damage in the scleractinian corals Agaricia agaricites f. purpurea and Porites astreoides. Bull mar Sci 30: $883-887$

Chamberlain JA Jr (1978) Mechanical properties of coral skeleton: compressive strength and its adaptive significance. Paleobiology 4:419-435

Chamberlain JA Jr, Graus RR (1975) Water flow and hydromechanical adaptations of branched reef corals. Bull mar Sci 25:112-125

Chapman G (1981) Individuality and modular organisms. Biol $J$ Linn Soc 15:177-183

Connell JH (1973) Population ecology of reef-building corals In: Jones OA, Endean R (eds) Biology and geology of coral reefs. Academic Press, London, p 271-324

Fang LS, Chen YWJ, Chen CS (1989) Why does the white tip of stony coral grow so fast without zooxanthellae? Mar Biol 103:359-363

Gladfelter EH (1982) White-band disease in Acropora palmata: implications for the structure and growth of shallow reefs. Bull mar Sci 32:639-643

Harper JL (1977) Population biology of plants. Academic Press, London

Harrison PL, Wallace CC (1990) Reproduction, dispersal and recruitment of scleractinian corals. In: Dubinsky $Z$ (ed) Ecosystems of the world 25. Coral reefs. Elsevier, Amsterdam, p 133-208

Highsmith RC (1982) Reproduction by fragmentation in corals. Mar Ecol Prog Ser 7:207-226

Highsmith RC, Riggs AC, D'antonio CM (1980) Survival of hurricane-generated coral fragments and a disturbance model of reef calcification/growth rates. Oecologia 46: $322-329$

Jackson JBC (1979) Morphological strategies of sessile animals. In: Larwood G, Rosen BR (eds) Biology and systematics of colonial organisms. Academic Press, London, $p$ 499-555

Kershaw KA (1962) Quantitative ecological studies from Landmannahellir, Iceland. I. Eriophorum angustifolium. J Ecol 50:163-169

Maragos J (1972) A study of the ecology of Hawaiian reef corals. PhD thesis, Unjversity of Hawaii, Honolulu

Meesters EH, Bak RPM (1993) Effects of coral bleaching on tissue regeneration and colony survival. Mar Ecol Prog Ser 96:189-198

Meesters EH, Bos A, Gast GJ (1992) Effects of sedimentation and lesion position on coral tissue regeneration. Proc 7 th int Symp Coral Reefs 1:681-688

Meesters EH, Noordeloos M, Bak RPM (1994) Damage and regeneration: links to growth in the reef-building coral Montastrea annularis. Mar Ecol Prog Ser 112:119-128

Palumbi RP, Jackson JBC (1983) Aging in modular organisms: ecology of zooid senescence in Steginoporella sp. (Bryozoa; Cheilostomata). Biol Bull 164:267-278

Pearse VB, Muscatine L (1971) Role of symbiotic algae (Zooxanthellae) in coral calcification. Biol Bull 141:350-363

Sokal RR, Rohlf FJ (1981) Biometry. WH Freeman and Co, New York 
Soong K, Lang JC (1992) Reproductive integration in reef corals. Biol Bull 183:418-431

Tunnicliffe $V(1978)$ The role of boring sponges in coral fracture. In: Levi C, Boury-Esnault N (eds) Biologie des spongiaires. Colloques Internationaux CNRS, Paris, p 309-315

Tunnicliffe $V(1981)$ Breakage and propagation of the stony coral Acropora cervicornis. Proc natl Acad Sci USA 78 $2427-2431$

This article was submitted to the editor
Van Veghel MLJ, Kahmann MEH (1994) Reproductive characteristics of the polymorphic Caribbean reef building coral Montastrea annularis. II. Fecundity and colony structure. Mar Ecol Prog Ser 109:221-227

Watt AS (1947) Contributions to the ecology of bracken. IV The structure of the community. New Phytol 46:97-121

Wlkinson L (1989) Systat: the system for statistics. Systat, lnc, Evanston, IL

Manuscript first received: September 23, 1994 Revised version accepted: January 23, 1995 